Research Article

\title{
Opportunistic Behavior Governance in PPP Projects: An Analysis Based on Trust Networks
}

\author{
Xiang Wang $\mathbb{D}^{1},{ }^{1}$ Yilin Yin $\mathbb{D}^{1,},{ }^{1,2}$ Jiaojiao Deng, ${ }^{2}$ and Zhichao $\mathrm{Xu}^{3}$ \\ ${ }^{1}$ College of Management and Economics, Tianjin University, Tianjin, China \\ ${ }^{2}$ College of Management, Tianjin University of Technology, Tianjin, China \\ ${ }^{3}$ Tianjin Rail Transit Group Co., Ltd., Tianjin, China \\ Correspondence should be addressed to Xiang Wang; engineer_wangxiang@163.com
}

Received 18 April 2020; Revised 5 December 2020; Accepted 4 February 2021; Published 16 February 2021

Academic Editor: Camelia Delcea

Copyright ( $\odot 2021$ Xiang Wang et al. This is an open access article distributed under the Creative Commons Attribution License, which permits unrestricted use, distribution, and reproduction in any medium, provided the original work is properly cited.

Stakeholders of PPP projects may induce opportunistic behaviors in long-term cooperation. Existing studies emphasized the inhibitory effect of trust on opportunistic behaviors, but most of them simplified the trust relationship into a two-subject perspective. From the perspective of social network analysis, this research constructs a network-level trust relationship between the stakeholders of PPP projects. The index analysis of the trust network shows that the PPP project stakeholders have obvious centrality and there are structural holes in the networks. From the perspective of the stakeholder alliance, different forms of alliances differ in the degree, betweenness, and closeness centrality of the trust network. On this basis, the analysis results of different trust network indicators match the corresponding preventive measures of opportunistic behavior, and this research provides comprehensive suggestions for project management.

\section{Introduction}

Construction projects using the public-private partnership (PPP) model can be regarded as a long-term social network structure [1]. All stakeholders in the social network structure contribute to the project performance, and their opportunistic behaviors will also have a negative impact on the project [2]. In order to solve this problem, some researchers found that trust relationships can inhibit opportunistic behaviors $[3,4]$. This indicates that the probability of opportunism behavior is low in a higher trust relationship environment. On the contrary, if the trust relationship between project stakeholders is shallow, opportunistic behaviors are more likely to occur [5].

Therefore, academic research on trust and opportunistic behavior mainly focuses on the dual trust relationship between the government and private investors $[6,7]$. This obviously ignores the network structure interwoven by the trust relations of other stakeholders, as well as the impact of trust networks on opportunistic behaviors $[5,8,9]$. In view of this, this research attempts to build a trust network among all stakeholders of PPP projects. Identifying weaknesses in the network indicates that opportunistic behavior is likely to occur [10]. On this basis, when different forms of stakeholder alliance are concluded, the model structure and indicators of the trust network change. By comparing the trust network density, centrality, and other indicators of each model horizontally, the enhancement or the weakening of the trust relationship in the social network can be determined, which reflects the reduction or the enhancement of the possibility of opportunistic behavior [7, 11], and management suggestions or prevention programs can be proposed on this basis.

\section{Theoretical Background}

2.1. Opportunistic Behavior and Trust. Trust is the foundation of cooperation, which can be transferred among stakeholders, and its role in PPP project management has been widely verified [12]. From the perspective of the social network, each stakeholder who trusts another stakeholder is willing to believe that the partner will not take advantage of 
others, which is consistent with the basic concept of trust; that is, one party in the binary relationship believes that the other party will not take actions harmful to them, even if the other party can do so [13].

Trust can inhibit opportunistic behavior, which has been confirmed by many fields of research [14, 15]. Therefore, uncertainties abound in PPP projects, and trust is often used as an incentive approach to the contractor, to reduce opportunistic behavior and improve project performance [16]. It should be noted that opportunistic behavior can be divided into two forms according to the stage: ex ante and ex post. Adverse selection is generally considered the main manifestation of ex ante opportunistic behavior, while moral hazard and rip-off are considered as ex post opportunistic behavior $[15,17]$. From the perspective of the relational contract, there are strong and weak opportunistic behaviors. The former indicates that it explicitly violates the agreement of the formal contract, while the latter violates the relational contract, even though it does not violate the formal agreement $[18,19]$. Opportunistic behavior can be divided into active opportunistic behavior and passive opportunistic behavior [20]. In this respect, the deliberate distortion of facts, deliberate misdirection, and active breach of contract are classified as active opportunistic behaviors, while indolence, omission, and evasion of obligations are classified as passive opportunistic behaviors $[21,22]$. In the practice of engineering project management, any form of opportunistic behavior will have a negative impact on project performance [4]. In the research for PPP project management, the inhibitory effect of trust on opportunistic behavior has been widely proved $[23,24]$. Researches have also shown that trust can reduce opportunistic behavior and improve the performance of PPP projects through different intermediary factors such as flexible contract, performance behavior, and perception of fairness $[25,26]$. However, previous researches only took the trust issue in the binary relationship between government and private investors as the object of discussion, and relevant questionnaires or scales also collected data based on the binary trust relationship $[8,23]$. This simplification of the trust relationship ignores the complex network-level trust structure in PPP projects.

There are many stakeholders in the PPP project, and they play an important role in each stage or the whole process of the PPP project [1]. However, opportunism occurs when one or more of the PPP stakeholders take advantage of the weaknesses of others and seek their own unilateral interests at the expense of others and/or the whole. In this regard, studies have focused on the important role of trust in reducing the opportunist behavior of PPP project stakeholders, and researchers believe that trust can reduce trade friction and promote the performance of PPP projects [15]. However, by analyzing the behaviors of stakeholders in PPP projects, some scholars found that one of the causes of disputes and frictions is the lack of trust in cooperation; therefore, positive measures for relationship governance should be taken [27]. However, most existing research focuses on the perspective of the binary trust relationship, which ignores the social relationship background rooted in the project, and the lack of diversity research in this aspect has attracted the attention of some scholars [5].

To sum up, PPP project stakeholders are in a common social network, and they make behavioral decisions based on mutual observation and contact. This interactive behavior rooted in the social network has a long history in contemporary society $[5,8]$. In this process, trust can reduce opportunistic behavior, but it is challenging for binary trust relationship researchers to explain the complex multiple relations in a social network. Research on the relationship between the social network and trust with regard to PPP projects is necessary to identify all the stakeholders of the trust relationship and to identify the influence of opportunistic behaviors among the stakeholders.

\subsection{Trust Network Based on the SNA Method. In recent} years, many scholars believe that the trust network should be further explored on the basis of the binary trust relationship. In this respect, earlier studies defined the trust network as a network of relationships in which people are willing to put valuable, important, long-term resources or businesses at risk due to other people's bad behavior $[15,28]$. On this basis, some scholars have analyzed the trust network from the perspective of public governance and the informal system [29]. There are studies that focused on the impact of trust networks in the management of higher education [30]. A few supply chain studies depicted the interaction between trust networks and opportunistic behaviors through characterizing a complex adaptive system [5]. However, the interpretation and analysis of the trust network are mainly focused on cryptography, computer science, and other fields and focus on the optimization of trust algorithms or the decentralization of a trust network [31].

In the field of construction management, there are few studies that focus on the systematic analysis of the trust network among the stakeholders. There are many studies on the application of social network analysis (SNA) to describe the project governance or risk management approaches with regard to the network relationship of engineering projects [32]. There are also studies that use the SNA method to comprehensively describe the relationship network among project stakeholders including trust, commitment, and cooperation [33]. Most of these studies have included the investigation and measurement of the trust relationship among the project stakeholders [34, 35], which lay the foundation for the characterization of the trust network.

This research explored the trust network between the various stakeholders in a PPP project by using the SNA method. The nodes in the trust network represent all stakeholders, the links between nodes represent the trust relationship of stakeholders, and the numerical weight of the links indicates the level of trust, which is obtained from the data analysis of the scale $[36,37]$. After the trust network is established, the indicators reflected include density, centrality, structural hole, and alliance, all of which can be analyzed. To be specific, the density of the trust network reflects the trust intensity of the overall network 
stakeholders. If the overall network density is large, it can indicate that the network has a high level of trust intensity among the stakeholders. The factional indicator reflects the group formed by stakeholders with a strong trust relationship in the trust network, which can reveal the imbalance of trust among the stakeholders in the network; that is, the core group has a close mutual trust and can dominate the trust atmosphere in the network [36,37]. The investigation of the centrality of the trust network can reflect the status and relationship among the stakeholders. Specifically, the degree centrality reflects whether the trust relationship is dense, by which the network center can be found. Betweenness centrality reflects the trust transfer and control ability among the stakeholders. The closeness centrality can describe the degree of trust of a stakeholder by other subjects, and the smaller the value, the more the stakeholder is at the core of the trust network [38]. However, structural hole analysis can reflect the nonredundant trust relationship between two stakeholders in the network, which enables the structural hole occupant to obtain and transmit trust information, and thus has more credibility than other members in the network [39].

\section{Network Model}

This research uses the method of social network analysis (SNA) to build the trust network model among the stakeholders of PPP projects. We used a wide range of questionnaires to obtain the trust degree of each stakeholder, and then conducted data analysis and model creation using UCINET software. The steps used are described in the following sections.

3.1. Identify PPP Project Stakeholders. The PPP mode has been adopted in construction projects in many countries. Although each country's project type and construction procedure are different, bidding for private investors is a common step. Therefore, this research takes the bidding process as the research point, which can make the research results universal and has significance for PPP projects in various countries or regions. Researchers have shown that bidding and contract terms have a significant impact on the performance of PPP projects [15]. However, there is no stable contractual relationship between all stakeholders of the project in the bidding stage. Therefore, it is a universal phenomenon that project stakeholders in this period are mainly linked by a trust relationship [40, 41]. In fact, PPP project stakeholders in the bidding stage mainly include the urban development department, financial department, project implementing institution, urban construction investment companies, other government departments, exploration and design companies, engineering consulting companies, potential private investors, financial institutions, and the public $[39,40]$. Among them, financial institutions typically include investment banks or foundations, while the urban development and financial departments are usually responsible for the development of the city and the management of the financial revenue and expenditures [44].
This research takes an urban rail transit PPP project as its object, mainly considering that this kind of project involves more stakeholders when using the PPP mode. Compared with other types of projects, these stakeholders have more opportunities to contact and exchange information during the whole process of the project $[15,45]$. Rail transit projects are generally located in big cities, and most of the participants are enterprises or departments with strong capabilities and a good reputation. They have a preliminary understanding of each other and can form a preliminary relationship of trust or distrust $[15,46]$. In addition, considering that rail transit projects typically have many experienced project participants, taking such projects as research objects can make the research conclusions have better applicability and generalizability. All of the above factors contribute to the accurate description of the trust relationship and the comprehensive description of the trust network.

3.2. Questionnaire Preparation and Validity Test. The questionnaire was divided into three parts. The first part was the background introduction of the research, which mainly explained that the trust relationship referred to in this research existed between the stakeholders of PPP projects, rather than the interpersonal trust relationship. The second part mainly collected the basic information of interviewees. The third part of the questionnaire drew on the previous results of trust relationship research and required interviewees to directly judge the trust degree of their own enterprises or institutions with regard to other stakeholders of the same project [47-49]. In this part, the Likert scale was adopted, and the scores from 1 to 5 represented "no trust," "occasional trust," "general trust," "more trust," and "fully trust" among the stakeholders $[11,50]$. This study identified 10 core stakeholders of PPP projects, and the scale in the third part contained 10 items to measure the trust degree of the respondents' own enterprises to other stakeholders of the same project $[29,51]$.

Studies have shown that four reasons will lead to the validity deviation of the results of the questionnaire [52]. In this research, measures were taken from the aspects of the questionnaire introduction, respondent screening, and item simplification to improve the credibility and validity of the survey results. First, to avoid the respondents being unclear about the research objectives, the respondents were limited to the staff from various stakeholders who had participated in the rail transit PPP project. Second, to avoid the interviewees' inability to accurately rate the degree of the trust relationship, the questionnaire specifically required interviewees to answer according to the projects they had participated in most recently. Third, to avoid the reluctance of interviewees to tell the truth, we did not collect the personal information of interviewees but only the data needed for the study. Finally, to avoid the interviewees being unable to understand all the content of the survey, the opinions of scholars in this field were obtained for the preparation of the questionnaire, and experts were invited to evaluate it after the first draft was developed. The words and sentence 
patterns of the items were simplified to make them easier to understand.

3.3. Collation of Scale Data. After the questionnaire was completed, the scale data from the same stakeholder was collected. Ignoring respondents' rating of their own company, the expected values of the data from the remaining nine items were taken as the scores of this stakeholder's trust degree to the other nine stakeholders [47, 53]. The data acquisition of the results showed that the quantitative data of the trust relationship between two stakeholders were not the same. For example, the average score for trust between consultants and potential investors is inconsistent. We took the average value of these two different values again to obtain the final score of trust between these two enterprises $[53,54]$. In this research, for instance, the trust degree of these two enterprises mentioned above was calculated as 2, based on the rounding principle.

3.4. Data Analysis and Processing. Despite the limitation of specific projects, this study directly conducted a questionnaire survey on the personnel who participated in the PPP project of urban rail transit in China. Likert scale was used to measure the degree of trust among stakeholders of PPP projects, which was based on the measurement scheme of trust relationship in the previous studies $[48,55]$. The scale values 1 to 5 represented the level of trust relationship among stakeholders from low to high $[34,35]$. There are a total of 219 respondents, all of whom have participated in the bidding phase of the urban rail transit PPP project in 2019. According to statistics, respondents are concentrated in 18 PPP projects, and the basic information of respondents is shown in Table 1. After the survey, the scores of 219 questionnaires were averaged, and the preliminary data analysis showed that trust exists in social networks, but the strength of the trust relationship varies. The trust relationship matrix in the bidding phase of the rail transit PPP project is shown in Table 2.

Note that the degree of the relationship was generally analyzed and defined by dichotomy in the SNA. The data in Table 2 were binarized, that is, the values " 2 " and " 1 " were set to indicate a weak trust relationship, and the value " 0 " was used. Values of " 3 " and above indicated a strong trust relationship, and the value "1" was used [56]. Then, we used NetDraw software to draw the structure of the trust network, which is shown in Figure 1. Based on the network model, the network density, centrality index, structure hole, and faction analysis were selected to investigate the microstructure of the trust network.

\section{Network Results Analysis}

4.1. Density and Centralization. The UCINET software was used to analyze the network density and centralization of the trust network constructed in this study. The analysis results are shown in Table 3. Trust network density is 0.5778 , and there is a relatively close trust relationship between $57.78 \%$ of the stakeholders. A value greater than 0.5 indicates that the trust network has a relatively concentrated center, and
TABLE 1: Characteristics of respondents.

\begin{tabular}{|c|c|c|}
\hline Background characteristics & Frequency & Percentage \\
\hline \multicolumn{3}{|l|}{ Enterprise type } \\
\hline Urban development department & 13 & 5.94 \\
\hline Financial department & 15 & 6.85 \\
\hline Implementing institution & 23 & 10.50 \\
\hline $\begin{array}{l}\text { Urban construction investment } \\
\text { companies }\end{array}$ & 19 & 8.68 \\
\hline Other government departments & 9 & 4.11 \\
\hline Exploration and design companies & 19 & 8.68 \\
\hline Engineering consulting companies & 36 & 16.44 \\
\hline Potential private parties & 41 & 18.72 \\
\hline Financial institutions & 33 & 15.07 \\
\hline Societal public & 11 & 5.02 \\
\hline \multicolumn{3}{|l|}{ Work experience } \\
\hline$<3$ years & 104 & 47.49 \\
\hline $3-5$ years & 74 & 33.79 \\
\hline $6-10$ years & 32 & 14.61 \\
\hline$>10$ years & 9 & 4.11 \\
\hline \multicolumn{3}{|l|}{ Distribution of projects } \\
\hline Northern China & 7 & 38.89 \\
\hline Southern China & 9 & 50.00 \\
\hline Other parts of China & 2 & 11.11 \\
\hline \multicolumn{3}{|l|}{ Size of projects } \\
\hline More than 10 billion RMB & 8 & 44.44 \\
\hline $5-10$ billion RMB & 5 & 27.78 \\
\hline Less than 5 billion RMB & 5 & 27.78 \\
\hline \multicolumn{3}{|l|}{ Job position } \\
\hline Manager of the headquarters & 49 & 22.37 \\
\hline Project/department manager & 74 & 33.79 \\
\hline $\begin{array}{l}\text { General management/technical } \\
\text { personnel }\end{array}$ & 96 & 43.84 \\
\hline
\end{tabular}

binary trust relationship is vulnerable to the influence of other stakeholders, which conforms to the actual situation of the rail transit PPP project. The degree centralization (in) is obviously greater than the degree centralization (out), which indicates that the direction and intensity of the trust relationship are unbalanced among the subjects. The betweenness centralization indicates that only $23.46 \%$ of the stakeholders can effectively deliver trust in the trust network.

4.2. Centrality Index. In order to analyze the core body of the trust network in rail transit PPP project bidding stage, the centrality function of the Ucinet software was used and the results are shown in Table 4. Financial institution, engineering consulting company, exploration and design company, and implementing institutions rank high in the order of point degree and center degree, indicating that they can be trusted by more stakeholders in the trust network of PPP project competitive bidding stage. At the same time, the stakeholders with a high degree of centrality are financial institutions and the urban development department institutions, which indicate that both of them can effectively deliver trust and have stronger control over the creation of trust atmosphere in the bidding stage of PPP projects.

However, the data analysis also shows that the indicators of the potential private company and the financial department in the competitive bidding stage of PPP project are 


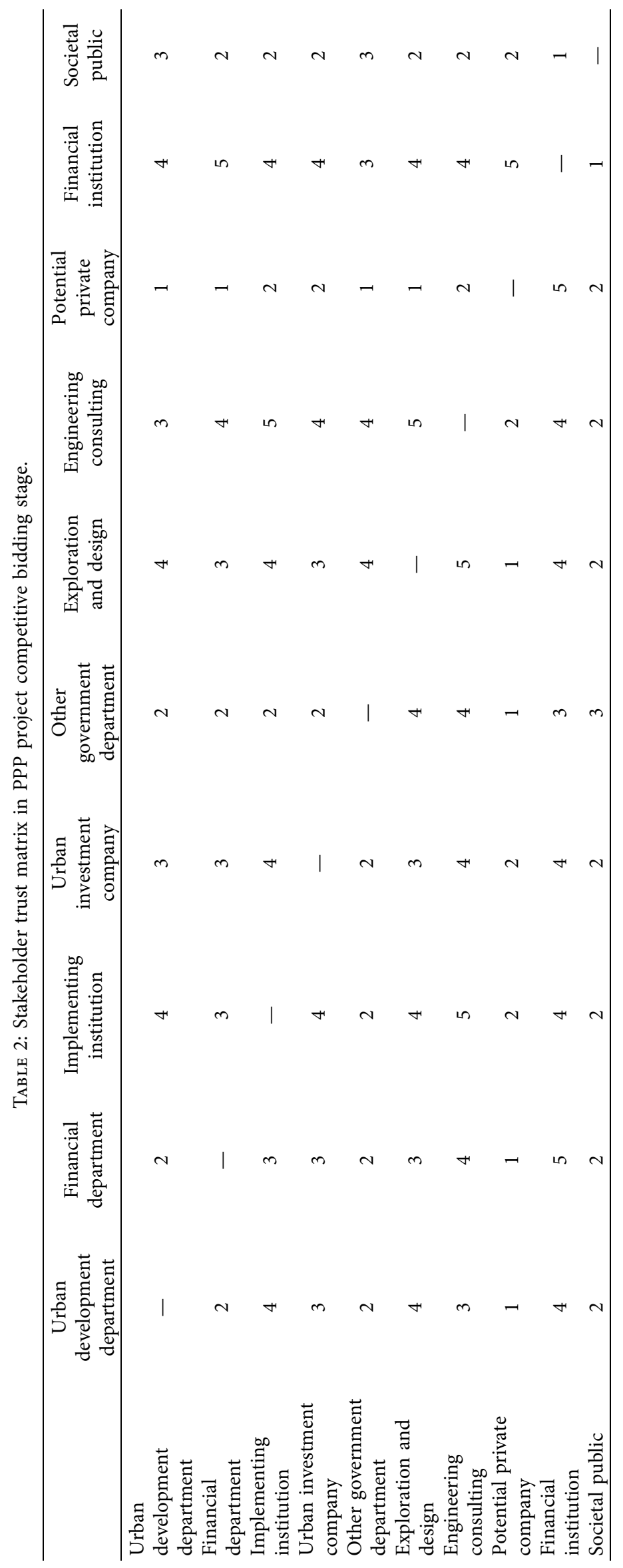




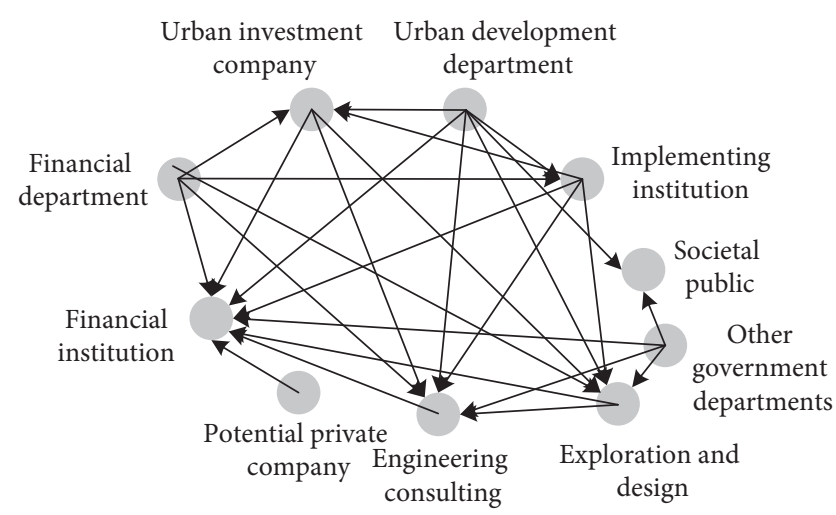

FIgURE 1: Trust network in competitive bidding stage of PPP project (Model 1).

TABLE 3: Indicators of trust network structure in the competitive bidding stage.

\begin{tabular}{lc}
\hline Indicators & Data \\
\hline Network density & 0.5778 \\
Standard deviation & 0.4939 \\
Degree centralization (out) (\%) & 31.605 \\
Degree centralization (in) (\%) & 48.889 \\
Betweenness centralization (\%) & 23.46 \\
Closeness centralization (\%) & 45.52 \\
\hline
\end{tabular}

mediocre. In particular, the centrality index data of the potential private company are all at a low level, which also confirms the conclusion of the existing research on the lack of initial trust in the Chinese society [57]. On the other hand, it also explains the reasons for the government's distrust of the potential private company before signing the contract. In this case, the government tends to adopt nonflexible contract terms to restrain opportunistic behaviors and risks from the private company [58].

In summary, the results of the study suggest that engineering consulting company, exploration and design company, and financial institutions are at the core of the trust network in the competitive bidding stage of PPP projects, because they have a large amount of project information or funds at this stage, and have an advantage in the information asymmetry situation.

4.3. Structural Hole. The effective size, efficiency, and limitation are usually used in the structural hole analysis. To be specific, the larger the effective scale is, the more unrestricted the point is in a trust network, otherwise. Efficiency represents the effective size of the point minus the redundancy of the network, and a larger index indicates that the point can establish trust relations more efficiently in the network. The restriction means that the stakeholder has the ability to use the structural hole in the network. The smaller the value is, the more the stakeholder's ability to control the trust atmosphere. Table 5 shows the calculation results of the trust network structure hole index. Financial institution, urban development department, and other government departments have relatively small restrictive indicators. They have extensive interactive relations in the trust network, and have the advantage of being trusted and the opportunity to control trust transmission. Moreover, the effective scale of these stakeholders is large, the nonredundant information is high, and they are in the structural hole, which brings the control ability of the network trust to them.

The potential private company and societal public have the highest efficiency, which is reflected in the fact that the source or degree of trust between them is relatively concentrated. The efficiency of other government departments is also high, which corresponds to the regulatory responsibilities of other government departments in practice.

4.4. Faction Analysis. This study uses the "core-edge" structure to analyze the trust network factions in the competitive bidding phase of rail transit PPP projects and identify the stakeholders in the core or the edge position. At present, no specific discriminant method is given for the "core-edge" structure. The "Continuous" functional module in the UCINET software is used to obtain the stakeholder Core degree arrangement of the trust network in the competitive bidding phase of the rail transit PPP project. The specific calculation results are shown in Table 6.

According to the trust network shown in Figure 1, the core structure is selected with more than seven connecting lines between nodes in this research $[59,60]$. Accordingly, financial institution, exploration and design company, and engineering consulting company are the core subject, the rest are in the edge structure. The core degree of financial institution, exploration and design company, and engineering consulting company has always been in the forefront, and they are the key nodes in the trust network. Among them, exploration and design company and engineering consulting company are consulting service institutions, and financial institutions provide project financing services. Their core position is highly consistent with the network center. In the competitive bidding phase of rail transit PPP projects, they are trusted by many stakeholders. In the reality of information asymmetry, the conclusion is closely related to the information superiority of the three $[4,61]$.

The government side of the PPP project generally includes financial department, urban development department, implementing agency, urban construction investment company, and other government departments. They have established interactive trust relationships with various stakeholders during the PPP project bidding phase. In the construction of urban infrastructure, the construction investment company shall be under the management of the government departments and execute the decisions at the same time. However, their demands and interests in specific projects are inconsistent, which will lead to deviation between decision-making and actual behavior. Therefore, if the urban construction investment company in the marginal structure of the trust network implements opportunistic behaviors in specific tasks, the consequences will be spread 
TABLE 4: Trust network centrality index.

\begin{tabular}{|c|c|c|c|c|c|}
\hline \multirow{2}{*}{ Stakeholder } & \multicolumn{2}{|c|}{ Degree centrality } & \multirow{2}{*}{ Betweenness centrality } & \multicolumn{2}{|c|}{ Closeness centrality } \\
\hline & Absolute & Relative & & Absolute & Relative \\
\hline Financial institution & 34.000 & 75.556 & 9.700 & 10.000 & 90.000 \\
\hline Exploration and design & 30.000 & 66.667 & 1.700 & 11.000 & 81.818 \\
\hline Engineering consulting & 33.000 & 73.333 & 1.700 & 11.000 & 81.818 \\
\hline Implementing institution & 30.000 & 66.667 & 0.325 & 12.000 & 75.000 \\
\hline Urban investment company & 27.000 & 60.000 & 0.325 & 12.000 & 75.000 \\
\hline Urban development department & 26.000 & 57.778 & 4.625 & 12.000 & 75.000 \\
\hline Financial department & 25.000 & 55.556 & 0.000 & 14.000 & 64.286 \\
\hline Other government department & 23.000 & 51.111 & 2.375 & 14.000 & 64.286 \\
\hline Societal public & 19.000 & 42.222 & 0.250 & 18.000 & 50.000 \\
\hline Potential private company & 17.000 & 37.778 & 0.000 & 18.000 & 50.000 \\
\hline
\end{tabular}

TABLE 5: Trust network structure hole index.

\begin{tabular}{lccc}
\hline & $\begin{array}{c}\text { Effective } \\
\text { size }\end{array}$ & Efficiency & Limitation \\
\hline $\begin{array}{l}\text { Urban development } \\
\text { department }\end{array}$ & 2.667 & 0.444 & 0.381 \\
Financial department & 1.000 & 0.200 & 0.509 \\
Implementing institution & 1.333 & 0.222 & 0.498 \\
Urban investment company & 1.333 & 0.222 & 0.498 \\
Other government & 2.500 & 0.625 & 0.367 \\
department & 2.429 & 0.347 & 0.447 \\
Exploration and design & 2.429 & 0.347 & 0.447 \\
Engineering consulting & 1.000 & 1.000 & 1.000 \\
Potential private company & 4.000 & 0.500 & 0.364 \\
Financial institution & 2.000 & 1.000 & 0.500 \\
Societal public & & & \\
\hline
\end{tabular}

TABLE 6: Core-edge analysis of trust network.

\begin{tabular}{lcc}
\hline Stakeholders & Degree & Structure \\
\hline Financial institution & 0.415 & \\
Exploration and design & 0.402 & Core \\
Engineering consulting & 0.402 & \\
\hline Implementing institution & 0.363 & \\
Urban investment company & 0.363 & \\
Urban development department & 0.321 & \\
Financial department & 0.306 & Edge \\
Other government department & 0.191 & \\
Societal public & 0.074 & \\
Potential private company & 0.059 & \\
\hline
\end{tabular}

to other stakeholders along the trust network. For example, the urban construction investment company fails to supervise the PPP project due diligence after it funds to set up the SPV company, which may lead to a surge in project cost, thus increasing the financial subsidy required for the project or raising the rail transit ticket price charged by the societal public. On the other hand, there are multiple government departments involved in PPP projects, some of which are on the edge of the trust network. These government departments, which have different demands on infrastructure projects than investment companies and therefore more emphasis on project oversight, generally work independently. Their supervision of projects can effectively curb opportunistic behavior.
In the purchasing stage of the PPP project, the societal public can play an important role in the supervision by public opinion [55]. It is worth noting that the public has a significant influence in the process of pre-project demonstration, land expropriation and demolition, construction or operation stage, and, therefore, all stakeholders of the project are willing to adopt the public's opinion in the project competitive bidding stage.

However, the potential private company has abundant information or resources about PPP projects but has not established a strong trust relationship with other stakeholders. Relevant studies have shown that the initial level of trust between the government and the potential private company is low before signing the contract [62]. The results of this study not only verified the above research conclusion but also extended it to the degree of trust between each stakeholder and the potential private company, which was more in line with the reality; in the competitive bidding stage, the potential private company did not establish a strong trust relationship with each stakeholder of the project.

\section{Trust Network Alliance}

It has been widely proved that trust has a restraining effect on the opportunistic behavior of the alliance in the case of unconstrained measures $[28,47]$. This research analyzes the data of the trust network indexes after the formation of the stakeholder alliance to identify the alliance form with higher trust and more stablility $[11,50]$. At the same time, the research analyzes the weak nodes of trust in different alliance situations and provides suggestions for the governance of opportunistic behaviors in different alliance forms [4]. The data analysis of this study indicates that the engineering consulting company, the exploration and design company, and the financial institution are at the core of trust network in the competitive bidding stage of urban rail transit PPP project, and this conclusion is helpful to expand the traditional research perspective of dual trust relationship between the government and the private company. At the same time, in view of the concept of trust corresponding to opportunistic behaviors adopted in this study, the adoption of opportunistic behaviors will have a broader and more farreaching impact on PPP projects. Based on this, it is 
necessary to analyze the alliance strategy of the core subjects of the trust network to identify which trust network structure can effectively resist opportunistic behavior. In the competitive bidding stage of PPP projects, engineering consulting company, exploration and design company have the most project information. In the case of information asymmetry, it is theoretically possible to implement opportunistic behavior through information superiority. In addition, the field of project management practice is vigorously promoting the extension of engineering consulting business to the whole-life-cycle of management. Therefore, in this study, the engineering consulting company and the exploration and design company are merged into a wholeprocess engineering consulting enterprise. The unique position of such enterprises in the trust network makes their opportunistic behavior more obvious.

Based on the above, the relatively optimal alliance form is determined by analyzing the trust network indicators under different alliance strategies. In addition, the most important dual subjects in the whole life cycle of PPP projects are still the government and the private company. In this stage, government departments are mainly embodied as implementing institutions, and implementing institutions tend to control projects through engineering consulting enterprise. Therefore, this study discusses the alliance of the potential private company, the financial institutions, and the whole-process engineering consulting enterprise, respectively. On this basis, different alliance strategies are considered. The trust alliance structure is shown in Figure 2. Model 2 represents the trust network of alliance of engineering consulting company and the exploration and design company; models 3 and 4, respectively, represent the alliance of potential private company and whole-process consulting enterprise, and alliance of potential private company and financial institution. Model 1 represents the original network (Table 2 and Figure 1), that is, the trust network without alliance strategy. The trust data after the alliance shall be determined according to the higher value. Then, the trust network density and center potential of each alliance calculated by Ucinet software are shown in Table 7 .

The formation of any alliance leads to an increase in the overall density of the trust network, which indicates that the trust of all stakeholders in the network is close. The betweenness centralization of model 2 is the largest, indicating that in the trust network of the alliance of whole-process engineering consulting enterprise, there are stakeholders that can effectively control trust resources (29.35\%).

However, the degree centralization of Model 3 is larger than other forms of alliance, and it has the lowest level closeness centralization, which indicates that the alliance form is in the central position of the trust network, and the alliance can form a strong trust atmosphere in the network. Then, Ucinet was used to calculate the centrality index, and the four model results were compared to reflect the impact of different alliance strategies on the trust network. The results are shown in Tables 8-10.

The overall analysis shows that financial institutions play an important role in the trust network, regardless of alliance or not. In addition, betweenness centrality of financial institutions, urban development department, and the alliance of potential private company and whole-process consulting enterprise in model 3 is high, indicating that they all have a strong ability to influence the trust atmosphere of the whole network.

From the point of view of degree centrality, each alliance is at the core of its trust network. However, from a horizontal perspective, the degree centrality of the private company and the whole-process consulting enterprise alliance is relatively low, which makes it easy to induce opportunistic behavior in the trust network it belongs to. Moreover, the degree centralization of model 3 is the largest compared with other models, indicating that the alliance in model 3 is at the core of the network. Therefore, if it implements an opportunistic behavior, it will have a great impact in the trust network. This kind of situation can be manifested as the consulting company embedded favorable terms to the potential private company in the bidding documents to help them win the bid. Then, in the bidding negotiation and the contracting process, the key clauses of the contract that are adverse to the private company will be concealed, so that the alliance can obtain excess profit during the cooperation period of the PPP project.

The betweenness centrality of the financial department is always kept at 0 , regardless of alliance or not, indicating that it cannot control or affect the trust relationship between other stakeholders. In fact, all PPP projects in China need the financial department to examine and approve the financial calculation or implementation plan in the early stage, based on which the project can enter the competitive bidding phase. However, the low betweenness centrality data of the financial department shows that it cannot effectively transmit the trust relationship. In other words, the preliminary data of the project approved by the financial department can only be regarded as a phased achievement and cannot have a substantial impact on the project bidding and contract signing. This provides an opportunity for alliance collusion and opportunistic behavior to spread in the bidding phase.

The closeness centrality of all stakeholders in model 3 is lower than other alliances or nonalliances model, indicating that the alliance in model 3 is the core, and it can bridge and transmit network trust to the greatest extent.

\section{Discussion}

6.1. Theoretical Implications. This study focused on the structure description and the effect analysis of the trust network among the PPP project stakeholders. We used the concept of network-level trust, and this concept has been reflected in the relevant research in the field of supply chain management $[5,8]$. The relevant indicators of the network structure in SNA theory were used to describe the structure of trust network quantitatively, which is a refinement of previous studies. The findings of this study also contribute to previous research on PPP project stakeholder management and network-level trust.

Some studies have shown that stakeholder management is important in PPP projects [63]. Some studies have also showed that all stakeholders of PPP projects, including the nearby residents, should be paid attention to, not just private 


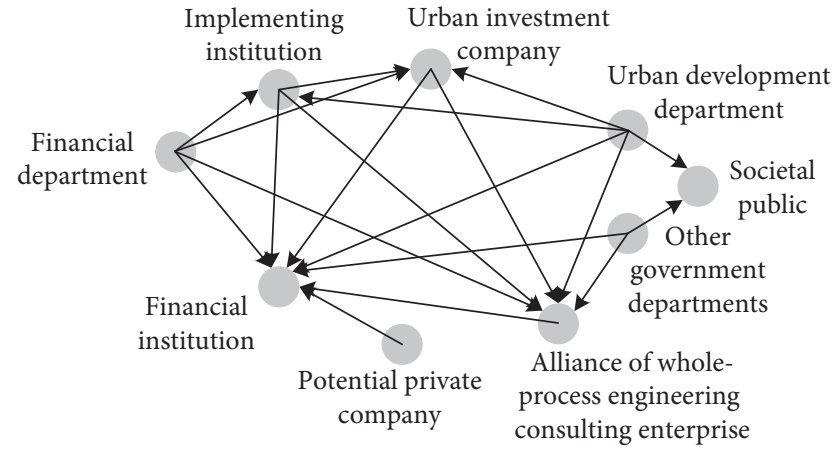

(a)

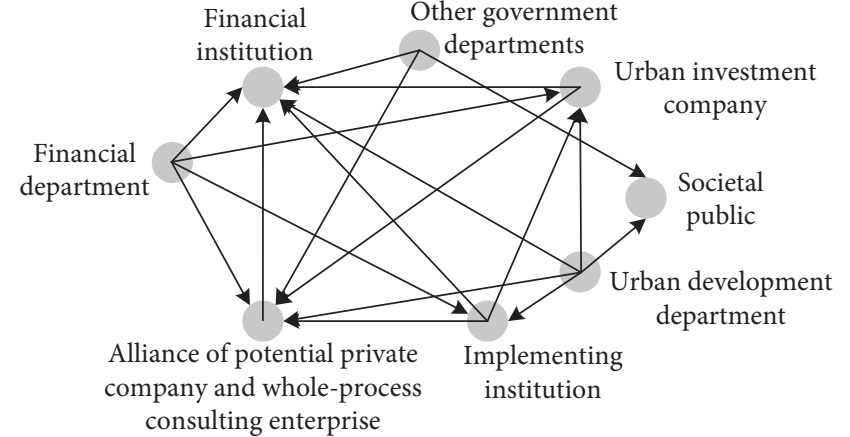

(b)

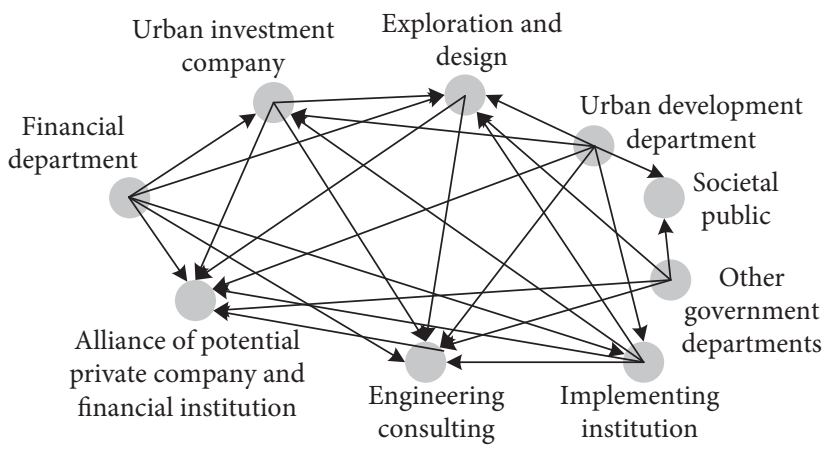

(c)

Figure 2: Trust network structure of different alliance strategies. (a) Model 2. (b) Model 3. (c) Model 4.

TABLE 7: Trust network alliance structure index.

\begin{tabular}{|c|c|c|c|c|}
\hline Index & Model 1 & Model 2 & Model 3 & Model 4 \\
\hline Network density & 0.5778 & 0.5278 & 0.6429 & 0.7222 \\
\hline Standard deviation & 0.4939 & 0.4992 & 0.4792 & 0.4479 \\
\hline $\begin{array}{l}\text { Degree centralization } \\
\text { (out) }(\%)\end{array}$ & 31.605 & 48.125 & 53.878 & 52.500 \\
\hline $\begin{array}{l}\text { Degree centralization } \\
\text { (in) }(\%)\end{array}$ & 48.889 & 53.750 & 60.408 & 55.313 \\
\hline $\begin{array}{l}\text { Betweenness } \\
\text { centralization (\%) }\end{array}$ & 23.46 & 29.35 & 12.47 & 12.08 \\
\hline $\begin{array}{l}\text { Closeness centralization } \\
(\%)\end{array}$ & 45.52 & 50.85 & 34.22 & 48.56 \\
\hline
\end{tabular}

investors or project contractors, to achieve the success of the project [64]. On this basis, establishing a trust relationship among the stakeholders of PPP projects has always been regarded as an effective means to improve project performance [65]. There are both formal relations based on law and contract, and informal relations based on emotion and trust between stakeholders [66]. However, stakeholders are more likely to face moral hazards, corruption problems, or legal risks in the context of informal relationships $[67,68]$. The specific manifestation in PPP projects is that some stakeholders form internal alliances, seek improper profits, collude, and seek rent [69]. However, previous studies have not carried out quantitative analysis in this field [42]. This study was designed to make a breakthrough in this aspect; we used social network analysis to construct the trust network structure of a China rail transit PPP project. Then, through the quantitative descriptions of indicators, such as the network density, centrality, structure hole, and trust alliance, we analyzed the different degrees of trust between the stakeholders and the influence of opportunistic behavior. This study opens up a new research perspective for the stakeholder management of PPP projects; that is, by analyzing various alliance forms in the trust network, the alliance forms with a high risk of opportunistic behaviors can be identified, and further research can be carried out accordingly.

This study combined the research on network-level trust with the SNA theory. On this basis, the trust network between the stakeholders of PPP projects can be described. Previous studies only discussed the dual trust relationship between the government and the private investors. In addition, previous studies analyzed the network-level trust in supply chain management using complex adaptive system methods to analyze and compare the trust networks and the opportunistic behaviors in different supply chain models, and it is believed that different trust networks will lead to different degrees of opportunistic behaviors $[5,70]$. It can be said that the definition of trust network in the field of supply chain is in line with the classic research conclusion; that is, the tendency of opportunistic behavior is generally reduced when multiple subjects are at a high level within the trust network. In an atmosphere of low trust, project participants are more likely to engage in speculative behavior $[5,70,71]$. This study follows this concept and applies it to the management of PPP project stakeholders. We conducted a 
TABLE 8: Index of degree centrality.

\begin{tabular}{|c|c|c|c|c|c|c|c|c|}
\hline \multirow{3}{*}{ Stakeholder } & \multicolumn{8}{|c|}{ Degree centrality } \\
\hline & \multicolumn{2}{|c|}{ Model 1} & \multicolumn{2}{|c|}{ Model 2} & \multicolumn{2}{|c|}{ Model 3} & \multicolumn{2}{|c|}{ Model 4} \\
\hline & Absolute & Relative & Absolute & Relative & Absolute & Relative & Absolute & Relative \\
\hline Financial institution & 34.000 & 75.556 & 34.000 & 85.000 & 30.000 & 85.714 & - & - \\
\hline Exploration and design & 30.000 & 66.667 & - & - & - & - & 31.000 & 77.500 \\
\hline Engineering consulting & 33.000 & 73.333 & - & - & - & - & 33.000 & 82.500 \\
\hline Implementing institution & 30.000 & 66.667 & 31.000 & 77.500 & 28.000 & 80.000 & 32.000 & 80.000 \\
\hline Urban investment company & 27.000 & 60.000 & 28.000 & 70.000 & 27.000 & 77.143 & 31.000 & 77.500 \\
\hline Urban development department & 26.000 & 57.778 & 31.000 & 77.500 & 30.000 & 85.714 & 34.000 & 85.000 \\
\hline Financial department & 25.000 & 55.556 & 25.000 & 62.500 & 24.000 & 68.571 & 27.000 & 67.500 \\
\hline Other government department & 23.000 & 51.111 & 23.000 & 57.500 & 22.000 & 62.857 & 26.000 & 65.000 \\
\hline Societal public & 19.000 & 42.222 & 26.000 & 65.000 & 23.000 & 65.714 & 27.000 & 67.500 \\
\hline Potential private company & 17.000 & 37.778 & 19.000 & 47.500 & - & - & - & - \\
\hline Model 2 & - & - & 33.000 & 82.500 & - & - & - & \\
\hline Model 3 & - & - & - & - & 32.000 & 91.429 & - & - \\
\hline Model 4 & - & - & - & - & - & - & 35.000 & 87.500 \\
\hline
\end{tabular}

TABLE 9: Index of betweenness centrality.

\begin{tabular}{lcccc}
\hline & \multicolumn{5}{c}{ Betweenness centrality } \\
Stakeholder & Model 1 & Model & Model & Model \\
& & 2 & 3 & 4 \\
\hline Financial institution & 9.700 & 9.417 & 2.417 & - \\
Exploration and design & 1.700 & - & - & 1.450 \\
Engineering consulting & 1.700 & - & - & 1.450 \\
Implementing institution & 0.325 & 0.417 & 0.417 & 0.200 \\
Urban investment & 0.325 & 0.417 & 0.417 & 0.200 \\
company & & & & \\
Urban development & 4.625 & 4.167 & 3.667 & 1.667 \\
department & 0.000 & 0.000 & 0.000 & 0.000 \\
Financial department & 2.375 & 1.833 & 1.333 & 0.667 \\
Other government & 0.250 & 0.333 & 0.333 & 0.250 \\
department & - & 2.417 & - & - \\
Societal public & - & - & 2.417 & - \\
Potential private company & 0.000 & 0.000 & - & - \\
Model 2 & - & - & - & 4.117 \\
\hline Model 3 & - & & & \\
Model 4 & &
\end{tabular}

quantitative analysis of different trust network alliance states and identified the unique status of the engineering consulting companies and financial institutions in the trust network. This finding is conducive to expanding the binary subject perspective of project management in the past and requires researchers to consider project management issues from the perspective of all stakeholders, instead of just focusing on the government managers and the contractor.

Researchers on the trust network in computer science have made a breakthrough, and many researchers have focused on the analysis of the trust network [51, 72]. The focus of its research was to obtain all possible directed paths between the source nodes and target nodes using a Depth First Search method, and then to simplify the complex trust network path into a directed series parallel graph to facilitate the inference and calculation of the trust relationship between network users [73]. A trust network, which was used to depict the trust relationship between Internet users and reflect the trust degree between users, was generated [74].
This study used social network analysis to depict trust networks, which is also the basic method of evaluating trust networks in the field of computer science [75]. The ideas and steps of the trust network analysis were further used to carry out computer simulations with actual data, which is of great significance to the research of trust network in PPP projects and even general engineering construction projects.

To sum up, this study used the concept of network-level trust and introduced the method of social network analysis to conduct the quantitative treatment of the trust network structure. On this basis, it identified and analyzed the trust network alliance of stakeholders of PPP projects. The results of this study expand the research horizon of PPP project stakeholders.

6.2. Management Implications. The findings of this study suggest that it is important to pay attention to the trust network structure among stakeholders and take measures to deal with opportunism. In a PPP project, the government mainly focuses on the improvement of the project's performance, while a private company mainly focuses on the profitability of the project. Therefore, the government should focus on the analysis of the structural characteristics of the trust network's stakeholders to avoid the opportunistic behavior caused by the pursuit of profit maximization.

First, the results of this study show that if the engineering consulting enterprise forms an alliance with a private company, it will be more trusted in the social network of stakeholders. The traditional assumption of profit maximization will lead to opportunistic behavior. To avoid this situation, in the bidding process, the tenderer is required to provide his or her previous project achievement certification and the information on how the private company won prior bids for the same type of project to help the government clarify the past cooperation experience between the engineering consulting enterprise and the private company.

Second, to avoid the opportunistic behavior of the private company and the consulting enterprise alliance, the government can also use a decentralized approach, namely, carry out third-party review of the consulting service's 
TABLE 10: Index of closeness centrality.

\begin{tabular}{|c|c|c|c|c|c|c|c|c|}
\hline \multirow{3}{*}{ Stakeholder } & \multicolumn{8}{|c|}{ Closeness centrality } \\
\hline & \multicolumn{2}{|c|}{ Model 1} & \multicolumn{2}{|c|}{ Model 2} & \multicolumn{2}{|c|}{ Model 3} & \multicolumn{2}{|c|}{ Model 4} \\
\hline & Absolute & Relative & Absolute & Relative & Absolute & Relative & Absolute & Relative \\
\hline Financial institution & 10.000 & 90.000 & 9.000 & 88.889 & 8.000 & 87.500 & - & - \\
\hline Exploration and design & 11.000 & 81.818 & - & - & - & - & 9.000 & 88.889 \\
\hline Engineering consulting & 11.000 & 81.818 & - & - & - & - & 9.000 & 88.889 \\
\hline Implementing institution & 12.000 & 75.000 & 11.000 & 72.727 & 9.000 & 77.778 & 10.000 & 80.000 \\
\hline Urban investment company & 12.000 & 75.000 & 11.000 & 72.727 & 9.000 & 77.778 & 10.000 & 80.000 \\
\hline Urban development department & 12.000 & 75.000 & 11.000 & 72.727 & 9.000 & 77.778 & 10.000 & 80.000 \\
\hline Financial department & 14.000 & 64.286 & 13.000 & 61.538 & 11.000 & 63.636 & 11.000 & 72.727 \\
\hline Other government department & 14.000 & 64.286 & 13.000 & 61.538 & 11.000 & 63.636 & 12.000 & 66.667 \\
\hline Societal public & 18.000 & 50.000 & 16.000 & 50.000 & 13.000 & 53.846 & 13.000 & 61.538 \\
\hline Potential private company & 18.000 & 50.000 & 16.000 & 50.000 & - & - & - & - \\
\hline Model 2 & - & - & 10.000 & 80.000 & - & - & - & - \\
\hline Model 3 & - & - & - & - & 8.000 & 87.500 & - & - \\
\hline Model 4 & - & - & - & - & & & 8.000 & 100.000 \\
\hline
\end{tabular}

results. That is, the government hires two engineering consulting enterprises at the same time. One of the engineering consulting enterprises acts as an independent watchdog to review the results of the other firm's consulting services.

Third, information disclosure is an effective way to eliminate information asymmetry and avoid opportunistic behavior. China's Ministry of Finance has published information about PPP projects on its official website, which can be viewed and monitored by the public. However, to build a more efficient trust network in PPP projects, it is suggested that the ministry add data analysis of key indicators of the project, such as project yield rate, discount rate, and construction and operation costs. The information disclosure time span of the current six months should be further shortened. Furthermore, the lifelong responsibility system for the quality of the consulting services shall be implemented, and the blacklist of consulting and private companies should be increased to publicize those who have failed to prove their ability to do worthy work. Finally, a section for online complaints and questions can be added to improve the participation of the public.

Fourth, in view of the important role of financial institutions in the trust network of the PPP projects, it is suggested that financial institutions play a greater role in the competitive bidding stage. For example, professional financial institutions should be invited to calculate the financing pressure of the project, analyze the financial solvency of the project, and serve as an important basis for bidding and procurement of PPP projects. In addition, according to the findings of this study, a business review of the financial institutions should be carried out in the bidding phase of the PPP projects to avoid the establishment of an alliance between financial institutions and private enterprises. The actual investments of financial institutions involved in various types of PPP projects should be evaluated so that it can be determined whether they are bound to specific private enterprises. Multiple bundling operations are more likely to increase opportunism with private enterprises.
Fifth, to improve the trust network density in the PPP projects, the government can learn from the Integrated Product Development (IPD) mode and adopt a form of the joint office. This action helps to raise the level of trust among various stakeholders. At present, PPP projects in many countries are still implemented in multiple stages, and the government relies on engineering consulting enterprises to track and manage the project. In this case, it is suggested the government set up a centralized office for each PPP project, and the relevant government departments, engineering consulting enterprises, financial institutions, and other enterprises will arrange for personnel to attend to the PPP project work in this office.

In general, the PPP model has not been extensively used in many countries with a variety of project categories and different business capabilities of project participants. Relatively speaking, engineering consulting enterprises, financial institutions, and private enterprises with more information and knowledge can take advantage of the information asymmetry to implement opportunistic behavior, which has been proven many times by engineering practices. This study focuses on the analysis of the trust network structure of stakeholders in PPP projects, hoping to reduce the probability of opportunistic behavior through the regulation of the trust network.

\section{Conclusion}

This study used the SNA method to depict the trust network of the stakeholders in the purchasing stage of a PPP project, and through the analysis of the trust network density, centrality, structural hole, trust alliance, and other indicators, it revealed the generation and transmission of opportunistic behavior. Unlike the dual subject perspective in the field of engineering project trust research, the findings of this study are conducive to the long-term stability of the trust network of PPP projects. It is important to reduce the spread of opportunistic behavior in projects and create a possibility for the sustainable development of PPP projects. 


\section{Data Availability}

The data used to support the findings of this study are available from the corresponding author upon request.

\section{Conflicts of Interest}

The authors declare that they have no conflicts of interest.

\section{Acknowledgments}

The authors acknowledge the National Natural Science Foundation of China (Project nos. 71472135 and 71402119) for the financial support. The authors also thank all the respondents and interviewees who participated in the survey and research.

\section{References}

[1] A. N. Chowdhury, P.-H. Chen, and R. L. K. Tiong, "Analysing the structure of public-private partnership projects using network theory," Construction Management and Economics, vol. 29, no. 3, pp. 247-260, 2011.

[2] O. E. Williamson, Contract, Ggovernance and Ttransaction Ccost Eeconomics, World Scientific, Singapore, 2017.

[3] J. B. Barney and M. H. Hansen, "Trustworthiness as a source of competitive advantage," Strategic Management Journal, vol. 15, no. 1, pp. 175-190, 1994.

[4] P. Lu, L. Qian, Z. Chu, and X. Xu, "Role of opportunism and trust in construction projects: empirical evidence from Cchina," Journal of Management in Engineering, vol. 32, no. 2, Article ID 05015007, 2016.

[5] A. Capaldo and I. Giannoccaro, "Interdependence and network-level trust in supply chain networks: aA computational study," Industrial Marketing Management, vol. 44, pp. 180195, 2015a.

[6] A. Aminah and K. Iqbal, "The trust-control nexus in public private partnership (PPP) contracts," Journal of Accounting and Public Policy, 2020.

[7] C. Tilly, "Cities, states, and trust networks: chapter 1 of cities and states in world history," Theory \& Society, vol. 39, no. 3-4, pp. 265-280, 2010.

[8] I. Giannoccaro and A. Iftikhar, "Is nNetwork tTrust bBeneficial fFor sSupply nNetwork rResilience? A sSimulation aAnalysis," International Federation of Automatic Control, vol. 52, no. 13, pp. 2437-2442, 2019.

[9] A. Zaheer, B. Mcevily, and V. Perrone, "Does trust matter? exploring the effects of interorganizational and interpersonal trust on performance," Organization Science, vol. 9, no. 2, pp. 141-159, 1998.

[10] R. Zhitao, H. Wenjing, and Y. Xin, "The influence factors of trust in PPP project based on social network analysis," Science \& Technology Progress \& Policy, vol. 033, no. 016, pp. 67-72, 2016.

[11] D. Wang, S. Fang, and K. Li, "Dynamic changes of governance mechanisms in mega construction projects in Cchina: the mediating role of opportunism," Engineering Construction \& Architectural Management, vol. 26, no. 4, pp. 723-735, 2019.

[12] S. Yun, W. Jung, S. H. Han, and H. Park, "Critical organizational success factors for public private partnership projects - a comparison of solicited and unsolicited proposals," Journal of Civil Engineering \& Management, vol. 21, no. 2, pp. 131-143, 2015.
[13] B. Mcevily and M. Tortoriello, "Measuring trust in organisational research: review and recommendations," Journal of Ttrust Rresearch, vol. 1, no. 1, pp. 23-63, 2011.

[14] M. Fink and A. Kessler, "Cooperation, trust and performance - empirical results from three countries," British Journal of Management, vol. 21, no. 2, pp. 469-483, 2010.

[15] G. Wu, H. Li, C. Wu, and Z. Hu, "How different strengths of ties impact project performance in megaprojects: the mediating role of trust," International Journal of Managing Projects in Business, 2020.

[16] Z. Xu, Y. Yin, D. Li, and G. J. Browne, "Owner"s risk allocation and contractor"s role behavior in a project: a parallelmediation model," Engineering Management Journal; EMJ, vol. 30, no. 1, pp. 14-23, 2018.

[17] D. N. Rahman, "Determinants of partner opportunism in strategic alliances: a conceptual framework," Journal of Business \& Psychology, vol. 25, no. 1, pp. 55-74, 2010.

[18] R. M. Kramer and R. J. Lewicki, "Repairing and enhancing trust: approaches to reducing organizational trust deficits," Academy of Management Annals, vol. 4, no. 1, pp. 245-277, 2010.

[19] Z. Wang, F. Ye, and K. H. Tan, "Effects of managerial ties and trust on supply chain information sharing and supplier opportunism," International Journal of Production Research, vol. 52, no. 23-24, pp. 7046-7061, 2014.

[20] S. H. Seggie, D. A. Griffith, and S. D. Jap, "Passive and active opportunism in interorganizational exchange," Journal of Marketing, vol. 77, no. 6, pp. 73-90, 2013.

[21] T. Hawkins, M. G. Knipper, and D. Strutton, "Opportunism in buyer-supplier relations: new insights from quantitative synthesis," Journal of Marketing Channels, vol. 16, no. 1, pp. 43-75, 2009.

[22] O. Williamson and T. Ghani, "Transaction cost economics and its uses in marketing," Journal of the Academy of Marketing Science, vol. 40, no. 1, pp. 74-85, 2012.

[23] L. Brogaard, "Business value public-private partnerships: the positive impact of trust and task-relevant competencies on business outcomes in PPPs," International Public Management Journal, vol. 2018, Article ID 1457107, 2018.

[24] H. U. Zhen, W. Lu, and S. O. Management, "The relationship among government shareholding,trust and project performance in PPP projects," Construction Economy, vol. 40, no. 05 , pp. 33-38, 2019.

[25] D. Maurya and A. K. Srivastava, "Managing partner opportunism in public€“-private partnerships: the dynamics of governance adaptation," Public Management Review, vol. 21, no. 9-10, pp. 1420-1442, 2019.

[26] S. Ying-Hong, W. Fang, and C. Xin-Yue, "The relationship between stakeholders" trust and cooperation efficiency in PPP," East China Economic Management, vol. 33, no. 04, pp. 148-155, 2019.

[27] S. Jayasuriya, G. Zhang, and R. J. Yang, "Exploring the impact of stakeholder management strategies on managing issues in PPP projects," International Journal of Construction Management, no. 1, pp. 1-13, 2020.

[28] D. Wang, S. Fang, and H. Fu, "Impact of control and trust on megaproject success: the mediating role of social exchange norms," Advances in Civil Engineering, vol. 2019, no. 1, pp. 1-12, Article ID 4850921, 2019a.

[29] T. Goodfellow, H. White, O. Morrissey, and K. Shadlen, "Political informality: deals, trust networks, and the negotiation of value in the urban realm," Journal of Development Studies, vol. 56, no. 1, pp. 1-17, 2020. 
[30] J. R. Posselt, "Trust networks: a new perspective on pedigree and the ambiguities of admissions," The Review of Higher Education, vol. 41, no. 4, pp. 497-521, 2018.

[31] F. Sabatini and F. Sarracino, "Online social networks and trust," Social Indicators Research, vol. 142, no. 1, pp. 229-260, 2018.

[32] J. O. Kereri and C. M. Harper, "Social networks and construction teams: literature review," Journal of Construction Engineering and Management, vol. 145, no. 4, pp. 03119001.1-03119001.10, 2019.

[33] X. Zheng, Y. Le, A. P. C. Chan, Y. Hu, and Y. Li, "Review of the application of social network analysis (SNA) in construction project management research," International Journal of Project Management, vol. 34, no. 7, pp. 1214-1225, 2016.

[34] V. R. Mohan and A. R. Paila, "Stakeholder management in infrastructure/construction projects: the role of stakeholder mapping and social network analysis (SNA)," Aweshkar Research Journal, vol. 15, no. 1, pp. 48-61, 2013.

[35] W. Swan, P. McDermott, and M. Khalfan, "The application of social network analysis to identify trust-based networks in construction," International Journal of Networking and Virtual Organisations, vol. 4, no. 4, pp. 369-382, 2007.

[36] N. Guersakal, A. Oguzlar, Z. B. Aydin, and S. Tuezuentuerk, "Measuring trust in an intra-organisational context using social network analysis," International Journal of Management \& Enterprise Development, vol. 6, no. 4, pp. 494-512, 2009.

[37] N. Guersakal, Z. B. Aydm, and S. Tuezuentuerk, "Comparing the departmental trust networks of a small and medium size textile enterprise using social network analysis," International Journal of Management \& Enterprise Development, vol. 11, no. 2, pp. 222-240, 2011.

[38] P. D. Meo, K. Musial-Gabrys, D. Rosaci, G.iuseppe M. L. Sarnè, and L. Aroyo, "Using centrality measures to predict helpfulness-based reputation in trust networks," ACM Transactions on Internet Technology, vol. 17, no. 1, pp. 1-20, 2017.

[39] Y. E. Riyanto and Y. X. W. Jonathan, "Directed trust and trustworthiness in a social network: an experimental investigation," Journal of Economic Behavior \& Organization, vol. 151, pp. 1-20, 2018.

[40] J. T. Karlsen, K. Graee, and M. J. Massaoud, "The role of trust in project-stakeholder relationships: a study of a construction project," International Journal of Project Organisation and Management, vol. 1, no. 1, pp. 105-118, 2008.

[41] R. C. Marques, "Regulation by contract: overseeing PPPs," Utilities Policy, vol. 50, no. FEB., pp. 211-214, 2018.

[42] C.hika Amadi, P.atricia Carrillo, and T.uuli Martin, "Stakeholder management in PPP projects: external stakeholders" perspective," Built Environment Project and Asset Management, vol. 8, no. 4, pp. 403-414, 2018.

[43] N. N. Khan and S. Puthussery, "Stakeholder perspectives on public-private partnership in health service delivery in Sindh province of Ppakistan: a qualitative study," Public Health, vol. 170, pp. 1-9, 2019.

[44] L. Gao and Z. Y. Zhao, "The evolutionary game of stakeholders" coordination mechanism of new energy power construction PPP project: a Cchina case," Sustainability, vol. 12, 2020.

[45] A. P. C. Chan, P. T. I. Lam, D. W. M. Chan, and et al., "Critical success factors for PPPs in infrastructure developments: Chinese perspective," Journal of Construction Engineering and Management, vol. 136, no. 5, pp. 484-494, 2010.
[46] d. J. Martin, R. Mu, S. Dominic, Y. Ma, and B. Xi, "Introducing public-private partnerships for metropolitan subways in Cchina: what is the evidence?" Journal of Transport Geography, vol. 18, no. 2, pp. 301-313, 2010.

[47] P. T. Chow, S. O. Cheung, and K. Y. Chan, "Trust-building in construction contracting: mechanism and expectation," International Journal of Project Management, vol. 30, no. 8, pp. 927-937, 2014.

[48] D. M. Rousseau, S. B. Sitkin, R. S. Burt, and C. Camerer, "Introduction to special topic forum: not so different after all: a cross-discipline view of trust," The Academy of Management Review, vol. 23, no. 3, pp. 393-404, 1998.

[49] C. Steven, Currall, and \& A. Timothy, "Measuring trust between organizational boundary role persons," Organizational Behavior \& Human Decision Processes, 1995.

[50] B.uskens Vincent, Social Networks and Trust, Kluwer Academic Publishers, Amsterdam, Netherlands, 2002.

[51] Z. Gong, H. Wang, W. Guo, and Z. Gong, "Measuring trust in social networks based on linear uncertainty theory," Information Sciences, vol. 508, pp. 154-172, 2020.

[52] L. Yan, L. Guo, and Y. Ning, "Understanding construction contractors' intention to undertake consummate performance behaviors in construction projects," Advances in Civil Engineering, vol. 2020, no. 1, Article ID 3935843, 11 pages, 2020.

[53] B. Liu, Q. Zhou, R. X. Ding, I. Palomares, and F. Herrera, "Large-scale group decision making model based on social network analysis: trust relationship-based conflict detection and elimination," European Journal of Operational Research, pp. 2-39, 2018.

[54] J. K. Pinto, D. P. Slevin, and B. English, "Trust in projects: an empirical assessment of owner/contractor relationships," International Journal of Project Management, vol. 27, no. 6, pp. 638-648, 2009.

[55] S. J. Lee and H. J. Yu, "Factors affecting public servants trust in citizens :a case study of south Kkorean central government officials," International Review of Public Administration, vol. 18, no. 3, pp. 85-114, 2013.

[56] C. T. Butts, Tools for Ssocial Nnetwork Aanalysis. R Package Version, 2014, http://CRAN.R-project.org/package=sna.

[57] L. Qiang and W. Na, "Perspective of reflective modernization theory to understanding trust crisis and reconstructing trust in Cchinese society," Future and Development, vol. 41, no. 2, pp. 23-27, 2017.

[58] B. G. Hwang, X. Zhao, and M. J. S. Gay, "Public private partnership projects in Ssingapore: factors, critical risks and preferred risk allocation from the perspective of contractors," International Journal of Project Management, vol. 31, no. 3, pp. 424-433, 2013.

[59] X. Shusheng, C. Wenqiang, and D. Jiaojiao, "Core safety risk management in urban underground engineering:structure optimization and alliance strategies," Management Review, vol. 29, no. 11, pp. 240-250, 2017.

[60] J. Yang, Y. Zhang, and L. Liu, "Identifying opinion leaders in virtual travel community based on social network analysis," in Proceedings of the 6th International Conference on HumanComputer Interaction HCI in Business, Government and Organizations. Information Systems and Analytics, pp. 276-294, Orlando, FL, USA, July 2019.

[61] S. Cai, M. Jun, and Z. Yang, "Implementing supply chain information integration in China: tThe role of institutional forces and trust," Journal of Operations Management, vol. 28, no. 3, pp. 257-268, 2010.

[62] K. Verhoest, J. Voets, and K. Van Gestel, "A theory-driven approach to public-private partnerships: tThe dynamics of 
complexity and control," Routledge, vol. 1, no. 11, pp. 200-222, 2013.

[63] C. Amadi, P. Carrillo, and M. Tuuli, "PPP projects: improvements in stakeholder management," Engineering Construction \& Architectural Management, vol. 27, no. 2, pp. 544-560, 2019.

[64] J. T. Karlsen, K. Graee, and M. J. Massaoud, "Building trust in project-stakeholder relationships," Baltic Journal of Management, vol. 3, no. 1, pp. 7-22, 2008.

[65] C. Amadi, P. Carrillo, and M. Tuuli, "Stakeholder management in public private partnership projects in Nigeria: towards a research agenda," in Proceedings of the 30th Annual Conference of the Association of Researchers in Construction Management, vol. 1, no. 1, pp. 423-432, Portsmouth, UK, September 2014.

[66] L. Wang, J. H. Y. Yeung, and M. Zhang, "The impact of trust and contract on innovation performance: the moderating role of environmental uncertainty," International Journal of Production Economics, vol. 134, no. 1, pp. 114-122, 2011.

[67] K. G. Provan, "Modes of network governance: structure, management, and effectiveness," Journal of Public Administration Research \& Theory, vol. 18, no. 2, pp. 229-252, 2008.

[68] T. Tsaturyan and R. Muller, "Integration and governance of multiple project management offices (pmos) at large organizations," International Journal of Project Management, vol. 33, no. 5, pp. 1098-1110, 2015.

[69] A. Rodríguez-Pose, P. Yannis, and T. Vassilis, "Politics and investment: eExamining the territorial allocation of public investment in Greece," Regional Studies, vol. 50, no. 7, pp. 1097-1112, 2016.

[70] A. Capaldo and I. Giannoccaro, "How does trust affect performance in the supply chain? the moderating role of interdependence," International Jjournal of Pproduction Economics, vol. 166, no. 8, pp. 36-49, 2015.

[71] M. W. McCarter and G. B. Northcraft, "Happy together?: iInsights and implications of viewing managed supply chains as a social dilemma," Journal of Ooperations Mmanagement, vol. 25, no. 2, pp. 498-511, 2007.

[72] A. Josang, R. Hayward, and S. Pope, "Trust nNetwork aAnalysis with sSubjective ILogic," in Proceedings of the Twenty-Ninth Australasian Computer Science Conference (ACSW 2006), CD Rom, pp. 85-94, Sydney, Australia, 2006.

[73] F. S. Gohari, H. Haghighi, and F. S. Aliee, "A semantic-enhanced trust based recommender system using ant colony optimization," Applied Intelligence, vol. 46, no. 2, 2017.

[74] H. Ying, L. Chengchao, Y. Richard, and H. Zhu, "Trust-based social networks with computing, caching and communications: a deep reinforcement learning approach," IEEE Transactions on Network Science and Engineering, pp. 1-1, 2018.

[75] G. Fang, L. Su, D. Jiang, and L. Wu, "Group rRecommendation rRobotics bBased on eExternal sSocial-tTrust nNetworks," in Proceedings of the 2nd EAI International Conference on Robotic Sensor Networks, Kitakyushu, Japan, November 2020. 